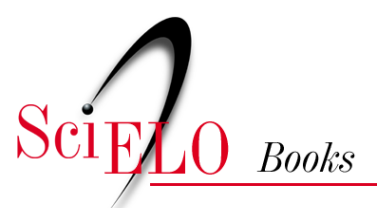

\title{
Capítulo 6. Cidades novas e o tempo
}

\author{
Ricardo Trevisan
}

\section{SciELO Books / SciELO Livros / SciELO Libros}

TREVISA, R. Cidades novas e o tempo. In: Cidades novas [online]. Brasília: Editora UnB, 2020, pp. 239-257. Pesquisa, inovação \& ousadia series. ISBN: 978-65-5846-158-6. https://doi.org/10.7476/9786558461586.0011.

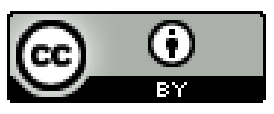

All the contents of this work, except where otherwise noted, is licensed under a $\underline{\text { Creative }}$ Commons Attribution 4.0 International license.

Todo o conteúdo deste trabalho, exceto quando houver ressalva, é publicado sob a licença Creative Commons Atribição 4.0.

Todo el contenido de esta obra, excepto donde se indique lo contrario, está bajo licencia de la licencia Creative Commons Reconocimento 4.0. 


\section{Cidades novas e o tempo}

Sexta parada: algum lugar do Centro-Norte de nosso país.

Para esta última parada, optei por não definir uma ou mais CNs, visando a introduzir aspectos relativos ao tema abordado, o tempo. Optei por levar os colegas viajantes a um período recente da história de nosso país, marcado pela continuação da “Marcha para o Oeste”, após a década de 1940, que avança pelo governo de JK e permeia os anos do Regime Militar até fins de 1980. Um corte temporal que revelará políticas econômico-sociais contribuindo para o surgimento de CNs, principalmente nas regiões Centro-Oeste e Norte do Brasil.

Já vimos em capítulos anteriores que, ao longo do século XX, inúmeras políticas públicas adotadas refletiram a prática de CNs em estreita relação com frentes dinâmicas de atividade econômica ou em apoio a medidas de arrancada ou intensificação do desenvolvimento. A lavoura cafeeira e a subsequente constituição da rede ferroviária de São Paulo e do Paraná nos inícios do século e a getulista "Marcha para o Oeste” (1938) exemplificaram tal processo. Aqui, veremos que todas elas foram seguidas pela Fundação Brasil Central (1943), coroadas pela transferência da própria capital federal para o planalto central (1960), mantendo-se após o golpe militar de 1964, quando um governo autoritário, centralizador e tecnocrático tirou partido das CNs, utilizando-as em planos implementados para os mais variados fins, sob a condução dos ideais de desenvolvimentismo e integração nacional.

Após uma fase preliminar centrada na construção intensiva de ferrovias em direção ao oeste paulista e ao norte paranaense (ver introdução do capítulo 1), na década de 1940 a frente pioneira se deslocaria rumo ao norte, objetivando a conexão e a ocupação da região amazônica via Centro-Oeste. Um dos primeiros indicadores 
desse deslocamento foi a fundação, em 1933, de Goiânia, nova capital de Goiás e segunda CN administrativa da República.

Além do controle do território, preocupação da Fundação Brasil Central (FBC), ${ }^{1}$ criada em 1943, a nova frente de urbanização era motivada também pelos interesses do capital imobiliário, das empresas ferroviárias e da agricultura intensiva para exportação. Algo verificável na Expedição Roncador-Xingu, um dos principais eixos da Marcha, que “deslocaria a fronteira para o sudoeste goiano e para os vales dos rios Araguaia, Xingu e Tapajós, construindo estradas, pistas de pouso, fazendas de gado, cidades, enfim, semeando modernidade pelas mãos dos expedicionários, bandeirantes do século XX” (MORAES, 2003, p. 82).

Logo esse quadro de urbanização seria alterado pela adoção de outras classes de ações promotoras de CNs, em especial: 1) a transferência da capital federal do Rio de Janeiro para o planalto central em 1960 - contribuindo com uma leva própria de CNs, até hoje em expansão: além de Brasília, as cidades-satélites brasilienses, como Taguatinga (1958) e Guará I (1967); 2) a construção da rodovia Belém-Brasília da década de 1950 à de 1970; e 3) as políticas específicas adotadas durante a ditadura militar, em atendimento a demandas geopolíticas e/ou de infraestrutura.

Ao longo do século passado, identificam-se ganhos consideráveis na infraestrutura nacional como suporte ao desenvolvimento, num primeiro momento restritos aos locais mais dinâmicos e à produção econômica neles em vigor - como as ferrovias do período cafeeiro. Foi o presidente Washington Luís (1926-1930) que, ao discursar no Congresso Nacional em 1927, lançou a semente do “rodoviarismo” em escala nacional, ${ }^{2}$ conforme defendeu: “Governar é povoar, mas não se povoa sem se abrir estradas e de todas as espécies. Governar é, pois, fazer estradas.” (UNB, 1972, p. 66). Bem mais tarde, em 1944, seria posto em prática o Plano Rodoviário

1 A sede da FBC foi localizada na CN de Aragarças (1943), na região noroeste de Goiás, estrategicamente construída para receber seus funcionários.

2 Como já fizera no estado de São Paulo, cuja política rodoviária data de 1913, por iniciativa justamente sua quando deputado estadual, acelerada durante seu mandato de governador, entre 1920 e 1924 (FICHER, 2005). 
Nacional, embora com resultados de pouca monta. Outra tentativa, de 1948, foi elaborada pelo deputado federal Jales Machado da Siqueira (1895-1975), que buscava incluir, na política rodoviária, a construção de rodovias perimetrais e radiais, interligando as diferentes regiões e tendo por foco o planalto central, onde deveria se localizar a futura capital da nação.

O Plano Rodoviário Nacional seria referência para o Plano Quinquenal de Obras Rodoviárias, elaborado no governo Juscelino Kubitschek (1956-1961) para:

[...] atender às necessidades sócio-econômicas mais prementes, compreendendo as regiões onde a economia atingirá maior expressão, e as regiões férteis de economia latente ou que, apesar do isolamento do oceano, explodiam e eram objeto de uma intensa e desordenada ocupação. (UNB, 1972, p. 68).

Para fomentar o mercado interno pela derrubada das barreiras de isolamento entre áreas mais e menos economicamente desenvolvidas, foram então propostas, entre outras, as rodovias Belém-Brasília, Brasília-Fortaleza, Brasília-Acre, Cuiabá-Santarém e Transamazônica, empreendimentos acelerados no governo militar, tendo por base o II Plano Nacional Rodoviário. As rodovias “plantadoras” de CNs contribuíram para “a instalação de 100.000 famílias” às suas margens, e, de quebra, controlaram e direcionaram o fluxo migratório (BRASIL, 1972, p. 28).

A rodovia Belém-Brasília (atual BR-153) - conhecida popularmente como a “Estrada das Onças” - possui mais de dois mil quilômetros de extensão, interligando a capital do Pará à capital federal, perpassando Maranhão, Tocantins e Goiás. Vinculada inicialmente à FBC, seu primeiro trecho, de Anápolis à CN de Ceres e depois a Uruaçu, foi implantado na década de 1940, após a criação da Colônia Agrícola 
Nacional de Goiás (Cang). ${ }^{3}$ Mas a sua data oficial é 15 de maio de 1958, quando foi promulgado o Decreto $n^{\circ}$ 43.710, criando a Rodobrás - comissão executiva responsável por sua construção, vinculada à Superintendência do Desenvolvimento da Amazônia (Sudam) e dirigida, inicialmente, pelo engenheiro agrônomo Bernardo Sayão. Apesar de inúmeros percalços na fase inicial, o propósito de integrar a Amazônia ao sul do país prosseguiria e, em 1968, quando a rodovia já contava com 120 núcleos urbanos e dois milhões de habitantes em sua área de influência, foi concluído o seu estudo de viabilidade econômica, o qual estabelecia o ano de 1973 como prazo final para a conclusão de sua pavimentação (BRASIL, 1971).

Essa estrada, assim como as demais posteriormente, corroboraria tanto o crescimento de núcleos urbanos existentes, retirando-os da economia de subsistência - como Porangatu, Uruaçu e Imperatriz, denominadas de “cidades renovadas”-, quanto o surgimento de CNs. Estas últimas podem ser divididas em dois tipos: os acampamentos da Rodobrás (aglomerados de poucas construções, localizados em trechos da rodovia que demandavam maior tempo de obra) e os novos núcleos de povoamento (implantados pontilhando distâncias relativamente iguais ao longo de seu traçado). Mais ainda, graças à dinamização econômica, somando-se às atividades rurais pré-existentes, surgiriam também CNs em função da prestação de serviços à estrada (postos de combustível) ou pelos serviços que a estrada proporcionava. No grupo de CNs da Belém-Brasília, encontram-se: Paragominas (PA), Estreito (MA), Araguaína (TO), Guaraí (TO), Paraíso do Tocantins (TO), Gurupi (TO), Alvorada (TO), Ceres (GO), Abadiânia (GO) e Alexânia (GO). Contudo, do ponto de vista urbanístico, tais núcleos nem sempre revelaram projetos minuciosamente elaborados (BRASIL, 1972).

3 Criada em 1940, no vale do rio São Patrício, município de Ceres, a Cang atraiu grandes levas de lavradores. Dado os seus resultados, na mesma década foram estabelecidas colônias semelhantes nos municípios de Rubiataba, Rialma e Carmo do Rio Verde, todos em Goiás (MORAES, 2003). 
Figura 16: Rodovia Belém-Brasília

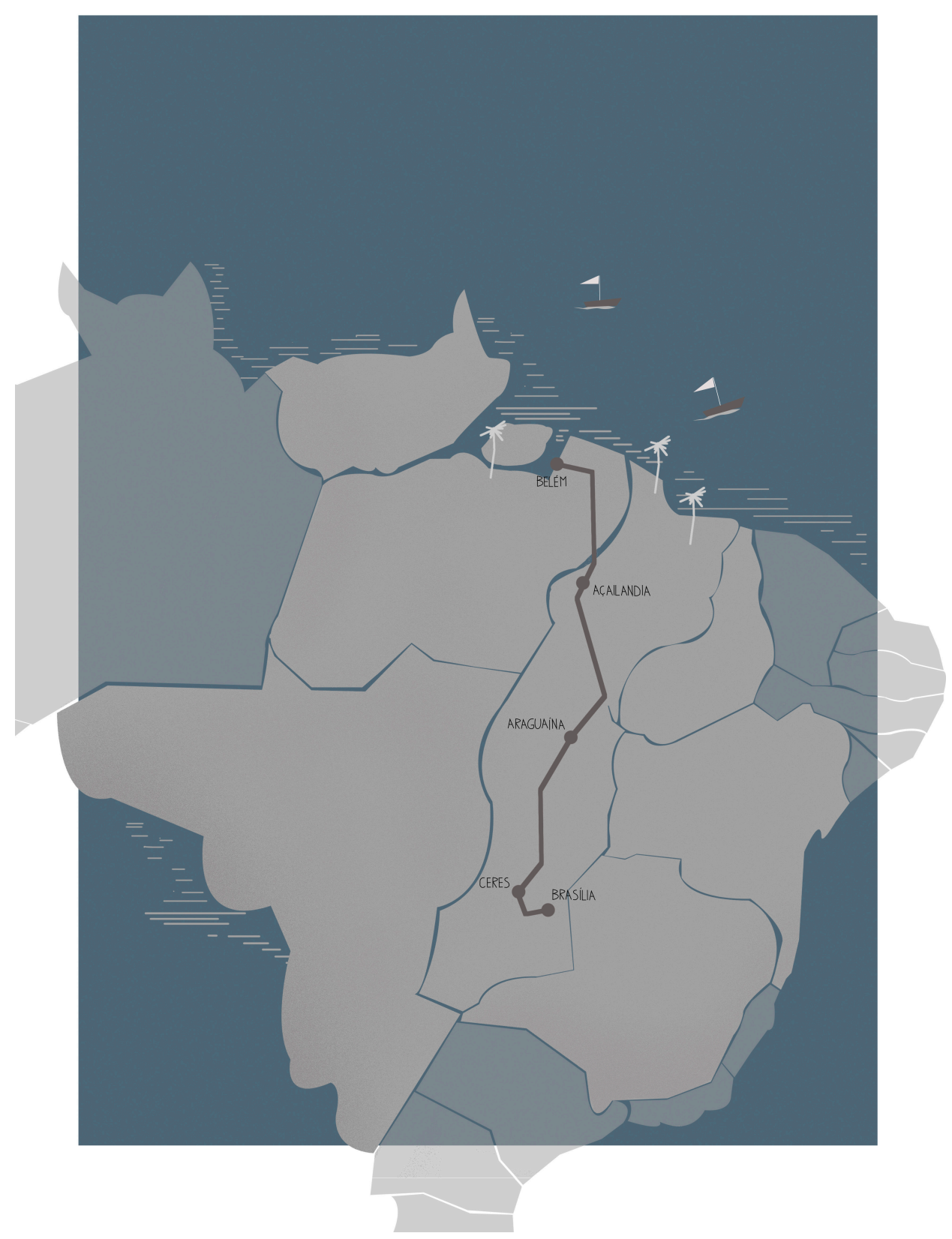


A urbanização advinda do incremento populacional proporcionado pela rodovia se deu de modo desordenado, alterando fisionomias e funções. Cidades dos séculos XVIII e XIX, como Uruaçu e Jaraguá, tiveram seu traçado original absorvido por novos loteamentos, e o antigo núcleo de Porangatu foi abandonado pela migração de seus habitantes rumo a um novo assentamento (UNB, 1972). No que se refere às CNs, em geral apresentavam planos similares, com traçado em malha ou linear, definição de trama viária rígida e regulamentação do uso do solo - salvo exceções, como Abadiânia que, realocada para uma nova sede, recebeu um traçado similar ao de Goiânia (patte-d'oie). Quanto à sua infraestrutura, dispunham de serviços insatisfatórios de água, luz e esgoto; como centralidade, diferenciavam-se das mais antigas por não terem a praça como local de maior importância e, sim, o comércio próximo à estrada.

Processo semelhante seria desencadeado pela construção da Transamazônica, fruto de "uma proposta concreta de hierarquização urbana feita pelos organismos competentes em função de um programa de colonização” (BRASIL, 1972, p. 14). O governo militar, ao enfrentar a velha problemática de povoamento de extensas áreas ainda devolutas, ${ }^{4}$ apresentou como solução a implantação de uma rede urbana de penetração, visando à segurança das fronteiras e à colonização planejada. O programa "Integrar para desenvolver” definia para a Amazônia duas linhas de ação: 1.) integração física, econômica e cultural; e 2.) expansão da fronteira econômica, absorção de excedentes populacionais de outras áreas e elevação do nível de renda e bem-estar na região (BRASIL, 1972, p. 79-80).

O seu plano de ocupação, coordenado pelo Instituto Nacional de Colonização e Reforma Agrária (Incra), consistia em criar áreas rurais produtivas, estendendo-se por 100 quilômetros de cada lado do complexo rodoviário e abrangendo aproximadamente 2.300.000 km² (BRASIL, 1972, p. 83). As áreas foram classificadas segundo um tipo funcional: lotes rurais, ocupações urbanas, reservas florestais

4 Até a década de 1970, a Amazônia, apesar de representar 3/5 da área do território nacional, abrigava apenas 7\% da população total brasileira (BRASIL, 1974). 
e biológicas, reservas industriais, reservas para obras de infraestruturas e áreas inaproveitáveis.

A rede urbana deveria obedecer a uma hierarquia, conforme a seguinte gradação e nomenclatura (BRASIL, 1972, p. 84-85):

- Agrovila (centro menor): comunidade rural-urbana oferecendo ensino primário, serviço social e de saúde, pequeno comércio e habitações;

- Agrópolis (centro de segunda ordem): comunidade urbano-rural contabilizando 22 agrovilas, com 6 mil habitantes cada; e

- Rurópolis (centro microrregional): comunidade de agrovilas e agrópolis, de vida urbana mais intensa.

Ao longo da Transamazônica, deveria haver uma agrópolis a cada 40 quilômetros e uma rurópolis a cada 140 quilômetros, induzindo ao estabelecimento de uma malha de CNs de baixa densidade, com cerca de 6,5 hab. $/ \mathrm{km}^{2}$. Tal escala crescente de urbanização proporcionaria, em condições ideais: flexibilidade, contato entre áreas predominantemente rurais e urbanas e novas opções de crescimento à luz das experiências acumuladas. As CNs deveriam ser concebidas como "uma concentração adequada dos ingredientes humanos, científicos, tecnológicos, financeiros, industriais, sociais, culturais, comerciais, e outros necessários ao funcionamento de certas atividades indispensáveis ao desenvolvimento sócio-econômico” (BRASIL, 1972, p. 377). As infraestruturas básicas previstas eram: apoio financeiro, áreas de estocagem e conservação; serviços escolares e de saúde; comércio atacadista e varejista; oficinas de reparos etc. Dentre as CNs da Transamazônica, a mais conhecida é Marabá (1973), no Pará.

Fato é que tais rodovias propiciaram o desenvolvimento econômico e a urbanização, embora, para além de tais objetivos, houvesse uma lógica de mercado. Ao saírem do papel, as rodovias nacionais visavam a expandir o mercado consumidor - levando produtos manufaturados das regiões mais industrializadas - e 
a facilitar a circulação de produtos agrícolas e minerais - oriundos das regiões mais isoladas. A Belém-Brasília deveria servir para escoar produtos agrícolas de Goiás e do Maranhão para Belém e São Paulo, sem necessariamente repercutir em retorno econômico para as regiões produtoras. Igualmente a Transamazônica, que tinha em primeiro plano a extração e exportação de riquezas, mas deixava de lado a preocupação em colonizar e potencializar o progresso regional (UNB, 1972).

A intensificação da ocupação da floresta amazônica também se valeu de planos distintos daqueles vinculados às rodovias. Trata-se de uma série de programas formulados e colocados em prática por diferentes Ministérios (Agricultura, Interior, Minas e Energia), buscando suprir o déficit habitacional, capacitar de infraestrutura o espaço intraurbano e ordenar a ocupação territorial por meio de planos regionais. Nos anos 1970, por exemplo, o I Plano Nacional de Desenvolvimento (I PND), o Programa de Integração Nacional (PIN) e o Plano Nacional Territorial (PNT) tinham por especificidade a integração e o desenvolvimento nacionais. A lista é longa e incluía ainda os planos Prodoeste, Polocentro, Provale, Proterra, Polamazônia e os projetos Aripuanã-Humboldt e Radam, todos de caráter colonizador e coordenados por superintendências específicas (como Sudam e Suframa) ou pelo Incra.

Sob o comando do Serviço Federal de Habitação e Urbanismo (Serfhau), CNs foram propostas não somente em faixas pioneiras, assistidas por rodovias interregionais (Belém-Brasília e Transamazônica), mas para a construção de polos siderúrgicos e petroquímicos e de hidrelétricas (como exemplificam as CNs citadas na introdução do capítulo 3).

Com a extinção do Serfhau em 1974, a continuidade do processo foi atribuída, primeiramente, à Comissão Nacional de Regiões Metropolitanas e Políticas Urbanas (CNPU, 1974-1979), orientada por seu II Plano Nacional de Desenvolvimento (II PND, 1974). Posteriormente, foi substituída pelo Conselho Nacional de Desenvolvimento Urbano (CNDU, 1979-1985), responsável pela Política Nacional de Desenvolvimento Urbano (PNDU, 1979). 
A CNPU, ao formular o II PND, delimitou algumas ações graduadas: controle, dinamização, disciplina, promoção e/ou contenção. Para as regiões Centro-Oeste e Norte, foram previstos programas abrangendo os núcleos urbanos da perimetral norte, do curso do rio Amazonas, da Transamazônica, do eixo Belém-Brasília, de cidades do Centro-Oeste e da região geoeconômica do Distrito Federal.

Um desses planos, o Programa de Polos Agropecuários e Agrominerais da Amazônia (Polamazônia), lançado no governo Geisel (1974-1979), consistia no investimento em 15 polos de desenvolvimento regional com recursos provenientes do PIN e do Proterra, visando a obras de infraestrutura, pesquisas mineralógicas e trabalhos de regularização fundiária. Áreas da “Amazônia Legal” foram selecionadas estrategicamente em função de suas potencialidades agropecuárias, agrominerais e agroindustriais: 1) Xingu-Araguaia; 2) Carajás; 3) Araguaia-Tocantins; 4) Trombetas; 5) Altamira; 6) Pré-Amazônia Maranhense; 7) Rondônia; 8) Acre; 9) Juruá-Solimões; 10) Roraima; 11) Tapajós; 12) Amapá; 13) Juruena; 14) Aripuanã; e 15) Marajó. Como apoio às frentes pioneiras, além do incremento econômico de núcleos existentes, deveriam ser criadas "23 CNs, de 8 a 80 mil habitantes, até o ano dois mil” (BRASIL, 1974, p. 63).

Dentre as áreas estipuladas, Aripuanã (MT) recebeu atenção especial do Ministério do Planejamento, do Interior e da Educação e Cultura e do governo estadual, por meio de convênio específico firmado em 1973. Denominado Projeto Aripuanã-Humboldt, previa: a implantação do núcleo pioneiro de Humboldt; a construção de rodovia ligando Humboldt a Vilhena (470 quilômetros); um programa de pesquisas florestais, de solos e recursos naturais; e outros de interesse científico. Como atrativo a mais para o capital privado e para imigrantes de outras regiões, entre Juruena e Aripuanã foram alienados cerca de dois milhões de hectares de terras a particulares. Estas permitiram o surgimento de inúmeras CNs como: Sinop (1974), Alta Floresta (1975), Juruena (1975), Juína (1977) e Paranaíta (1978).

Como último episódio dessa empreitada inacabada de colonização da hinterlândia, o estado de Goiás foi desmembrado com a criação do estado de 
Tocantins, após a redemocratização em 1985. Dessa alteração resultou Palmas, a mais recente cidade capital projetada do país.

Independentemente da postura ideológica e dos meios nada democráticos adotados pelo regime militar - infelizmente sendo justificados pelos fins - para colocar suas empreitadas em prática, pôde-se verificar uma produção urbana inédita. Não somente em termos numéricos, dada a criação de municípios e a resultante urbanização, mas também pela diversidade de estratégias e métodos aplicados, profissionais envolvidos, tipologias urbanísticas empregadas e, acima de tudo, pelas profundas consequências que teve para a organização territorial e demográfica do país.

Um período da história pautado no avanço de frentes pioneiras, modificando as divisas do desenvolvimento, que gerou “a construção progressiva de uma rede urbana de apoio, hierarquizada segundo suas funções, para sua eficiente incorporação à economia nacional”. (BRASIL, 1971, p. 10). Um planejamento que tomou partido da CN como uma ferramenta essencial, deveras utilizada como mecanismo de efetivação de ações desenvolvimentistas - apoio a construção de infraestruturas de grande porte e a exploração de novas atividades econômicas - e de ações integradoras - base atrativa de migração para as regiões Centro-Oeste e Norte. ${ }^{5}$

Um cenário revelador do sexto e último elemento do DNA das CNs: o tempo. Tempo presente antes (gestação), durante (nascimento) e após (desenvolvimento), a fundação dessas e das demais CNs conectando empreendedor, função, sítio, profissional e projeto num único propósito. Tempos relativamente precisos em cada caso e que marcam a transformação de uma CN em uma cidade.

\footnotetext{
5 A estratégia estava "na conciliação da agricultura e da indústria, com o aumento do emprego da mão de obra e a busca da expansão do mercado interno” pela “incorporação de novas áreas à economia nacional” (BRASIL, 1971, p. 111).
} 


\subsection{Da cidade nova à cidade}

Brasília é construída na linha do horizonte. Brasília é artificial. Tão artificial como devia ter sido o mundo quando foi criado. Quando o mundo foi criado, foi preciso criar um homem especialmente para aquele mundo. Nós somos todos deformados pela adaptação à liberdade de Deus. Não sabemos como seríamos se tivéssemos sido criados em primeiro lugar e depois o mundo deformado às nossas necessidades. Brasília ainda não tem o homem de Brasília. Se eu dissesse que Brasília é bonita veriam imediatamente que gostei da cidade. Mas se digo que Brasília é a imagem de minha insônia vêem nisso uma acusação. Mas a minha insônia não é bonita nem feia, minha insônia sou eu, é vivida, é o meu espanto. É ponto e vírgula. Os dois arquitetos não pensaram em construir beleza, seria fácil: eles ergueram o espanto inexplicado. A criação não é uma compreensão, é um novo mistério. - Quando morri, um dia abri os olhos era Brasília. Eu estava sozinha no mundo. Havia um táxi parado. Sem chofer. Ai que medo. - Lucio Costa e Oscar Niemeyer, dois homens solitários. - Olho Brasília como olho Roma: Brasília começou com uma simplificação final de ruínas. A hera ainda não cresceu.

Clarice Lispector, Os primeiros começos de Brasília, 20/6/1960 (LISPECTOR, 1984, p. 452)

A Brasília visitada por Lispector no início dos anos 1960 - a imagem de uma maquete em tamanho natural, a constituição de uma cidade em tempo real - nos direciona para um aspecto peculiar às CNs. Nelas, o tempo é exclusivo - “tempo de curta duração”. É o tempo próprio do empreendedor, da função escolhida e do local estratégico, seguindo lógicas político-econômico-sociais do 
momento; é o tempo presente na formação do projetista e refletido nos estilos de arquitetura e urbanismo em voga; é o tempo específico, aqui utilizado para compreender e conceituar as CNs.

Em artigo para a revista La Géographie de l'Histoire, os historiadores Camille Vallaux e Jean Brunhes (apud PENNA, 1958, p. 10-11) diferenciam a CN (por eles denominada de "cidade artificial”) da "cidade natural” por aspectos temporais. Para eles, a cidade natural apresenta uma "formação lenta, seguindo à sorte do desenvolvimento dinástico e resultante da combinação de elementos muito complexos e por vezes contraditórios”; a CN é criada repentinamente, dentro de um tempo relativamente preciso frente à amplitude de sua história, e por vontades claras e objetivas.

Ou seja, uma velocidade de constituição urbana diferente, assim conceituada pelo urbanista Vincent Fouchier (apud DIEBOLD; LEMONIER, 2001, p. 14, tradução nossa): ${ }^{6}$

As CNs parecem viver mais rápido que as demais, numa sociedade contemporânea que se transforma igualmente de modo mais e mais rápido. Elas são privadas de uma base e de uma permanência que constituem a história ou o patrimônio antigo; também a rapidez das evoluções, o peso dos fenômenos econômicos e demográficos, a obsolescência das formas urbanas são nelas mais sensíveis.

E mesmo que seu processo de materialização dure anos ou séculos, o tempo de uma CN é sempre a expressão de circunstâncias imperativas numa conjuntura crucial, um marco decisivo em sua história.

6 "Les villes nouvelles semblent vivre plus vite que les autres, dans une société contemporaine qui bouge aussi de plus en plus vite. Ils sont privés d'un socle et d'une permanence qui constituent l'histoire ou l'ancien patrimoine; la vitesse de l'évolution, le poids des phénomènes économiques et démographiques et l'obsolescence des formes urbaines y sont également plus sensibles." 
Ademais, se o tempo faz parte do processo das CNs, as CNs revelam características de seu tempo. Ao possuírem um urbanismo e uma arquitetura, estes refletem os tipos então predominantes e fazem das CNs, por vezes, museus a céu aberto - um retrato fidedigno dos estilos vigentes, verificados em Versalhes, Serra do Navio, Brasília e Marne-la-Vallée. Na França, as villes nouvelles foram, ao seu tempo, a novidade da prática urbanística. Segundo o político Jean-Pierre Combe:

Economia de energia, redes de calor, selo de qualidade, redes de cabos televisivos, grande prêmio de arquitetura, equipamentos integrados, programa pedagógico de construções solares, novas técnicas de construções, avanços espetaculares em transporte urbano: a lista é longa de inovações colocadas em prática nas cidades novas ao curso dos anos 1970 e hoje reproduzidas e desenvolvidas em outras cidades, entre as mais dinâmicas. (apud SMADJA, 1987, p. I, tradução nossa). ${ }^{7}$

São informações físicas e evolutivas que permitem ao estudioso e pesquisador de CNs situá-las na linha temporal da história (“tempo de longa duração”), ${ }^{8}$ com dados melhor captados após uma divisão estabelecida. Ao tripartir o tempo das CNs em ciclos, construção, fundação e desenvolvimento preliminar, busco revelar suas especificidades e mostrar fatos importantes conectados a cada um deles.

7 “Économies d'énergie, réseaux de chaleur, label de qualité, réseaux de télévision par câble, architecture du grand prix, équipements intégrés, programme pédagogique de construction de bâtiments solaires, nouvelles techniques de construction, avancées spectaculaires en matière de transport urbain : la pratique dans les villes nouvelles au cours des années 1970 et aujourd'hui reproduite et développée dans d'autres villes, parmi les plus dynamiques.”

8 Para efeito de estudos, a data a ser considerada como origem de cada CN pode variar, sendo sempre escolhida a mais antiga e não a de fundação, seja ela: a decisão do empreendedor, a data do concurso para o projeto, o lançamento da pedra fundamental. Para Brasília, considero o ano de 1957, e não o de 1960, como sua origem. Datas mais distantes do período de fundação devem ser analisadas e mencionadas nos estudos, como o período de delimitação do quadrilátero do Distrito Federal pela Missão Cruls (fins do século XIX). 
O primeiro, ciclo de construção ou ciclo gestacional, é o mais importante para entender e compreender as CNs. Trata-se do período no qual os demais atributos compositivos estão envolvidos, delimitados pela decisão do empreendedor e pela inauguração da CN. Ações como planejamento, projeto e construção caracterizam-no, possibilitando ao novo núcleo tomar forma e propiciar condições mínimas de habitabilidade e urbanidade aos seus futuros morados.

O período dessa primeira etapa varia conforme a necessidade, o jogo de interesses, o tamanho e outras especificidades ligadas ao processo de cada CN. Variam desde prazos mais curtos, como Brasília (três anos; 1957-1960) e Goiânia (quatro anos; 1933-1937), até prazos mais longos, como Santos (14 anos; 1896-1910) e Barcelona (20 anos; 1855-1875).

Processos rápidos podem ser verificados igualmente na Itália e na França. No governo de Mussolini, as città di fondazione "brotaram em alguns meses. A primeira pedra de Littoria foi colocada em 30 de junho de 1932 e sua inauguração foi em 18 de dezembro de 1932; Sabaudia foi construída entre agosto de 1933 e abril de 1934; e Pontínia entre outubro de 1934 e abril de 1935” (VALLAT, 2001, p. 175, tradução nossa). ${ }^{9}$ Na França, a criação das villes nouvelles foi decidida num curto período. Em 1965, o ato que sancionou o nascimento das CNs francesas foi um plano territorial inovador e ambicioso (GUYARD, 1982), coordenado pela “Direção Geral do Distrito da Região de Paris”, com as cinco CNs fundadas ainda no início dos anos 1970. Agilidade que qualifica as villes nouvelles como "realizações originais, tanto em resultados como em procedimentos de implementação" (SUDOUR, 1987, p. 42, tradução nossa). ${ }^{10}$

Paralelamente, há processos mais arrastados, como os identificados na Coreia do Sul e na Polônia. No país asiático, a CN de Kangnam demorou 15 anos, entre 1970 e 1985, para ser fundada ao sul do rio Han, possuindo três distritos distintos

9 “[...] germé dans quelques mois. La première pierre de Littoria a été posée le 30 juin 1932 et inaugurée le 18 décembre 1932; Sabaudia a été construit entre août 1933 et avril 1934; et Pontínia entre octobre 1934 et avril 1935.”

10 “[...] réalisations originales, à la fois en termes de résultats et de procédures de mise en œuvre." 
e áreas residenciais para classes mais abastadas (DAEWOO CORPORATION, 1998). Já na Polônia, o tempo gestacional mais largo de suas CNs se justifica pela “demora na implementação de vários estágios de desenho. Uma razão burocrática e não técnica” (WAWRZYNSKI, 1986, p. 37, tradução nossa). ${ }^{11}$

Com a cidade relativamente constituída, apta a funcionar, segue-se o segundo período, ciclo de fundação ou nascimento da CN, marcado pela entrega da cidade aos seus futuros habitantes: uma data simbólica para a história de cada CN.

Trata-se de um flash, um momento de clareza frente ao período precedente bem como ao seu desenvolvimento. Tal precisão é fixada pela presença, na maioria dos casos, por um dia, um mês, um ano de fundação. Isso fica claro com a CN de Ali Mendjeli (Argélia): proposta inicialmente em 1974 (data referencial para estudos), sua pedra inaugural foi colocada somente em 1991, sendo ocupada por moradores a partir de 10 de abril de 1999, data de sua fundação (BOUMAZA, 2006).

Após o conhecimento público da existência da CN, vem o ciclo de desenvolvimento preliminar, quando a cidade fervilha com a chegada de novos habitantes, novas construções e pelos arremates finais no grande canteiro de obras. Momento de transformação rápida, se comparado com cidades de origem espontânea, que permitirá à nova cidade construir uma identidade própria. Período que pode demorar, segundo condições político-econômico-sociais, de alguns anos a décadas.

É durante esse ciclo que as previsões (população e dimensão) realizadas durante seu planejamento são colocadas à prova. Na Austrália, a CN de Monarto foi planejada para alcançar suas metas em dez anos (RUSHMAN, 1976). Na França, os projetos urbanos das villes nouvelles surgiram com uma previsão de 30 a 40 anos para atingir a população máxima e uma possível independência em relação à cidade-mãe (TILLIETTE, 1985). Na Inglaterra, o plano da nova “cidade-campo” de Tillingham Hall, fundada em 1985, recebeu um programa de investimentos de 10

11 “[...] a delay in the implementation of various stages of design. A bureaucratic and non-technical reason $[\ldots] ”$. 


\section{Cidades novas}

anos, até que a cidade alcançasse o fim de sua fase de desenvolvimento preliminar (SHOSTAK; LOCK, 1985).

Em alguns países em via de desenvolvimento, as CNs foram resultados de “projetos ad hoc, concebidas para responder às necessidades criadas por programas de desenvolvimento regional ou nacional (de escala local ou nacional), respostas urgentes ou imediatas aos problemas de refugiados ou de empresas industriais particulares”. (SAFIER, 1977, p. 4, tradução nossa). ${ }^{12}$ Poucas dentre elas fizeram parte de uma política de longo prazo de redistribuição da população de um país. Porém, o crescimento destas CNs se mostrou mais rápido e mais forte que suas homólogas inglesas e francesas.

A CN de Kourou, na Guiana Francesa, planejada para sediar o Centre Spacial Guyanais (1964), de domínio francês, foi exemplo desse rápido desenvolvimento, conseguindo, em uma década, chegar à sua população estipulada (SAFIER, 1977). Brasília, 50 anos após sua fundação, mesmo não atingindo a população prevista para o Plano Piloto, se tornou “uma verdadeira aglomeração urbana após um longo período de juventude problemática, a eterna crise de adolescente” (MATHIEU, 2008, entrevista). Uma cidade amadurecida rapidamente, trazendo consigo uma dezena de jovens cidades-satélites.

Essa variação temporal está condicionada a um conjunto de fatores não previstos durante o ciclo gestacional. Segundo Vincent Fouchier (apud DIEBOLD; LEMONIER, 2001, p. 13, tradução nossa), ${ }^{13}$ as CNs “foram planejadas num período de evolução demográfica e econômica cujos efeitos não foram similares ao de seu desenvolvimento”. Na Antiguidade, antigos núcleos coloniais romanos no Oriente Médio foram redesenhados após sua independência, conforme aspectos socioculturais locais (KOSTOF, 1999). Nos EUA, a CN de Circleville, em Ohio, teve seu

12 “[...] projets ad hoc conçus pour répondre aux besoins créés par les programmes de développement régionaux ou nationaux (échelle locale ou nationale), les réponses urgentes ou immédiates aux problèmes de réfugiés ou d'entreprises industrielles particulières.”

13 "Les villes nouvelles ont été planifiés dans une période d'évolution démographique et économique dont les effets n'étaient pas similaires à ceux de son développement." 
traçado modificado após sua fundação em 1810 por questões especulativas do solo urbano. Na Espanha, o projeto da CN de Riera de Caldes teve que ser redimensionado após crises econômicas e políticas nos anos 1970 (CARRERAS, 1986).

Figura 17: Circleville

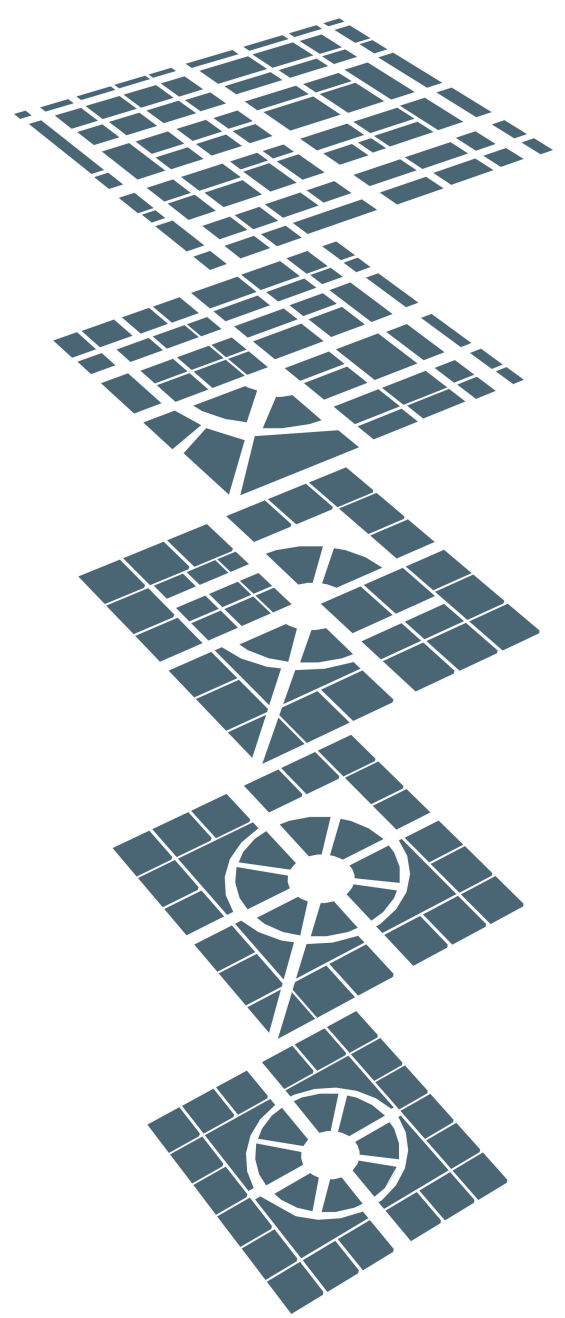


Além disso, nem toda cidade que apresente um rápido crescimento pode ser considerada uma CN. Na Polônia, 24 cidades apresentaram tal evolução entre as décadas de 1960 e 1970, dentre as quais somente quatro correspondem à nossa definição de CN, construídas segundo um urbanismo bem elaborado. Para Haumont (1997a, p. 85, tradução nossa), ${ }^{14}$ a origem de tal crescimento urbano acelerado deve-se, no caso polonês, a:

[...] cidades despovoadas durante ou logo após a guerra; cidades com rápido desenvolvimento após o descobrimento de jazidas de carbono ou cobre; cidades concebidas como centros importantes de industrialização socialista e de descongestionamento de cidades antigas; cidades operárias concebidas para abrigar trabalhadores de grandes usinas; cidades que se desenvolveram graças à industrialização ou à função administrativa.

A maturidade de uma CN - o tornar-se uma cidade - é conquistada quando ela adquire identidade própria, somada à sua emancipação e independência político-econômica (municipalização). Como exemplo específico, na França, a administração de suas CNs foi determinada pela Lei Boscher, de 10 de julho de 1970, mas sem clareza ou definição de qual instituição teria responsabilidade de fato sobre as villes nouvelles. Anos mais tarde, o cargo foi firmado no Établissement Public d'Aménagement (Estabelecimento Público de Planejamento), que se constituiu como monopolizador do papel de planejador: comprava os terrenos, os equipava, preparava os projetos da Zone d'agglomération nouvelle (Zona de aglomeração nova) e vendia os direitos de construção. Seu conselho era formado por metade de eleitores e metade de altos

14 “[...] villes dépeuplées pendant ou peu après la guerre; villes en développement rapide après la découverte de gisements de carbone ou de cuivre; les villes conçues comme des centres importants d'industrialisation socialiste et de décongestion des villes anciennes; villes ouvrières conçues pour loger les ouvriers des grandes usines; développés par l'industrialisation ou par des fonctions administratives." 
funcionários, embora o poder real pertencesse ao diretor, nomeado diretamente pelo primeiro-ministro (GUYARD, 1980). De modo mais objetivo, Paul Delouvrier (apud MONTAGU; SOKOLSKY, 1995, s.p., tradução nossa) $)^{15}$ afirmou que uma CN passa a ser uma cidade "quando seus cemitérios estiverem cheios”.

Independentemente dos critérios utilizados para qualificar as CNs como "cidades normais", o fato é que elas chegam a esse patamar em alguns anos ou décadas. Salvo quando fatores e contextos não as levam à morte, como ocorrido com CNs de exploração mineral em Goiás durante o ciclo do minério (séculos XVIII e XIX) e a experiência de Fordlândia na Amazônia, a cidade industrial de Henry Ford nos trópicos, atualmente tomada pela floresta. Casos que não desfazem a importância e a riqueza desse tipo urbanístico presente ao longo da história e vivo em diversas civilizações. Um tipo urbanístico atemporal em sua aplicabilidade, porém temporal em sua essência.

15 “[...] quand vos cimetières sont pleins.” 